\title{
Embryonic Development of the Avian Sternum and Its Morphological Adaptations for Optimizing Locomotion
}

\author{
Eleanor M. Feneck*, Sorrel R. B. Bickley and Malcolm P. O. Logan *(D)
}

Citation: Feneck, E.M.; Bickley, S.R.B.; Logan, M.P.O. Embryonic Development of the Avian Sternum and Its Morphological Adaptations for Optimizing Locomotion. Diversity 2021, 13, 481. https://doi.org/ $10.3390 / \mathrm{d} 13100481$

Academic Editors: Raul E. Diaz and Eric Buffetaut

Received: 29 July 2021

Accepted: 27 September 2021

Published: 29 September 2021

Publisher's Note: MDPI stays neutral with regard to jurisdictional claims in published maps and institutional affiliations.

Copyright: (c) 2021 by the authors. Licensee MDPI, Basel, Switzerland. This article is an open access article distributed under the terms and conditions of the Creative Commons Attribution (CC BY) license (https:// creativecommons.org/licenses/by/ $4.0 /)$.
Randall Centre of Cell and Molecular Biophysics, Guy's Campus, King's College London, London SE1 1UL, UK; sorrel.bickley@sarcoma.org.uk

* Correspondence: eleanor.feneck@kcl.ac.uk (E.M.F.); Malcolm.logan@kcl.ac.uk (M.P.O.L.)

\begin{abstract}
The sternum is part of the forelimb appendicular skeleton found in most terrestrial vertebrates and has become adapted across tetrapods for distinctive modes of locomotion. We review the regulatory mechanisms underlying sternum and forelimb development and discuss the possible gene expression modulation that could be responsible for the sternal adaptations and associated reduction in the forelimb programme found in flightless birds. In three phylogenetically divergent vertebrate lineages that all undertake powered flight, a ventral extension of the sternum, named the keel, has evolved independently, most strikingly in volant birds. In flightless birds, however, the sternal keel is absent, and the sternum is flattened. We review studies in a variety of species that have analysed adaptations in sterna morphology that are related to the animal's mode of locomotion on land, in the sky and in water.
\end{abstract}

Keywords: sternum; Tbx5; locomotion; limb development; evolutionary adaptation; flightlessness

\section{Introduction}

The Devonian period (420-350 MYA) saw significant adaptive radiation of fishes and the first water-to-land transition of vertebrates, an event that required significant adaptations to anatomical structures, especially those involved with air breathing and locomotion. By studying the fossil record, palaeontologists have classified the sarcopterygian (lobe-finned fish) as the closest ancestor of tetrapods, having skeletal elements homologous to the stylopod and zeugopod of tetrapod limbs, illustrating the evolutionary origin of limbs with digits [1]. Analysis of tetrapod ancestors can also help in understanding the origins of limb-associated structures, such as the sternum and the many adaptations of this structure that have occurred during evolution. Although the fossil record has provided clues to the evolutionary origins across diverse phylogenies, recent advances in genomic studies of living species have revealed adaptations in the conserved genes associated with the respiratory and nervous systems that have contributed to the evolution of terrestrial organisms [2,3]. The actinopterygians (ray-finned fish) are evolutionarily divergent from sarcopterygians (lobe-finned fish), however, regulatory elements that control limb and lung development are conserved in actinopterygian ancestors. This suggests the limb-related regulatory elements were established before the emergence of tetrapods [3].

Most evolutionary studies of the appendicular skeleton have focused on the skeletal adaptations in the limb and shoulder girdle, with only a small number of studies giving attention to the acquisition of other associated structures of the appendicular skeleton, such as the sternum. A comparable lack of evolutionary studies devoted to sterna are in part a consequence of the sterna of early tetrapods being cartilaginous, meaning remains have not been as well preserved as those of ossified bone, creating a gap in the fossil record of the early evolution of the sternum. We review the development and adaptations of the sternum in terrestrial vertebrates and discuss how similar modifications in sternum morphology, across a range of evolutionarily divergent species, are associated with specialised modes of locomotion. We propose genetic mechanisms that could underlie sternum development 
and adaptation. We also discuss how the common developmental origin and shared gene regulatory networks controlling formation of the sternum and forelimb appendicular skeleton provides an explanation for the reduction in both sternum and wing elements seen in flightless birds, such as ratites.

\section{Evolution and Development of the Sternum}

\subsection{Sternal Anatomy}

The sternum is a bone, present in the ventral midline of the thorax of most terrestrial vertebrates, which form joints with the clavicles and the ventral ends of the ribs. In placental mammals, the sternum is segmented, composed of the manubrium at the clavicular end, a sternal body and a caudal extension, the xiphoid process. Over the course of mammalian evolution, the sternum has reduced in parallel with adaptations to the shoulder girdle, with the loss of the interclavicle and coracoids found in monotremes. These adaptions provide the forelimb with more variable mobility [4]. The body of the sternum is composed of sternabrae, which can differ in number across different species due to sternabrae either fusing or remaining separated. In amphibians and lizards, the sternum is usually present as a cartilaginous plate, while in aves, it is largely ossified but not segmented. The sternum strengthens the body wall by forming a ventral closure and helps protect the internal visceral organs. The muscles that are attached to the sternum support forelimb locomotion and aid breathing. The sternum is an attachment site for the pectoral muscles [5] and the anatomy of these muscles can vary amongst terrestrial vertebrates. In quadrupeds the pectoral muscles play a critical role in lifting the body from the ground, and, in arboreal species, in hanging from trees. In birds capable of powered flight, the sternum provides an important attachment of both the $m$. pectoralis and $m$. supracoracoideus that are the prime movers of the downstroke and upstroke of the wings, respectively. In the vertebrate transition to land, acquisition of the pectoral muscles and their muscle attachment to the sternum would therefore have been a key acquisition to enable most terrestrial locomotion, with subsequent adaptation of these structures that enabled specialised locomotory abilities.

\subsection{Sternum Development}

Sternal precursor cells were originally proposed to originate from somites, perhaps not surprisingly given the final ventromedial location of the mature sternum and its close association with the ribs, which are derived from the axial mesoderm. However, grafting experiments in chick demonstrated that sternal precursors are not derived from the somites [6], which led to the proposition that sternal progenitors may, alternatively, originate in the lateral plate mesoderm (LPM). Further lineage experiments in chick demonstrate LPM cells ventral to the forelimb buds ultimately form the sternum. From their initial lateral positions, sternal progenitors migrate ventromedially to form two sternal bars that fuse at the midline and form a union with the ventral ends of the ribs and thereby close the thoracic cavity.

The T-box transcription factor, Tbx5, plays an essential role in sternum formation. Sternal defects, along with heart and forelimb deformities, are part of the characteristic abnormalities present in the congenital disease, Holt Oram syndrome, which is caused by mutations in TBX5 [7]. Tbx5 is expressed throughout the forelimb-forming LPM encompassing the domain of cells that contains the sternal precursors. In $T b x 5$ conditional mouse mutants, all elements of the appendicular skeleton, including the sternum, fail to form. Runx1-expressing sternal precursors are present initially in Tbx5 mutants, but fail to migrate, remaining in their original lateral location (Figure 1, from [8]) and ultimately are lost, suggesting that $\mathrm{Tbx} 5$ and its downstream targets control the migration of sternal precursor cells ventromedially [8]. 

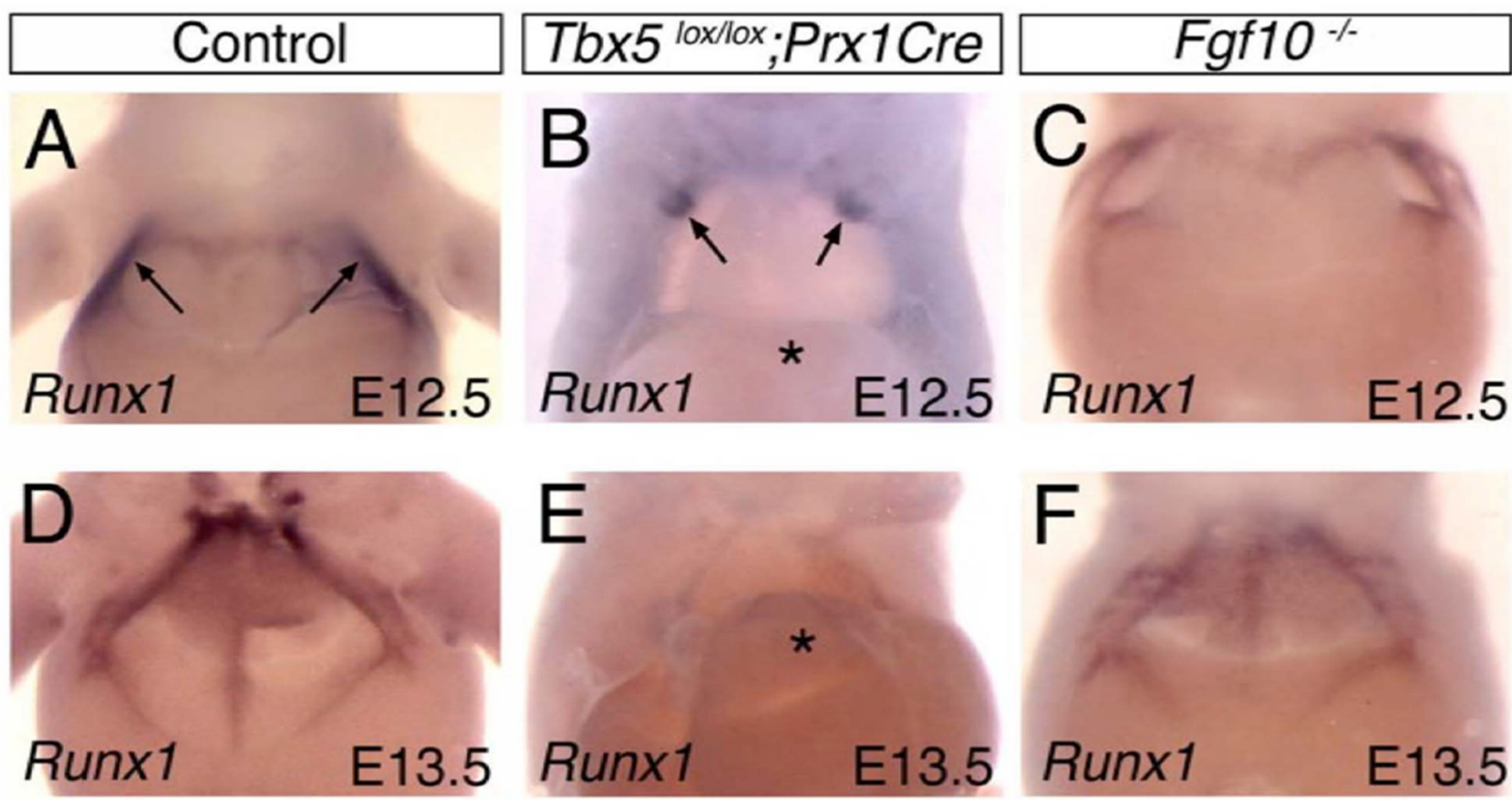

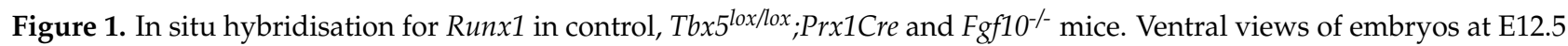
(A-C) and E13.5 (D-F). Runx1 is expressed in the sternal bands (arrows) in control (A,D) and Fgf10-/- $(\mathbf{C}, \mathbf{F})$ embryos, but is restricted to a region of the ventral body wall in E12.5 Tbx $5^{\text {lox } / l o x}$; Prx 1 Cre mice (arrows, B) and is not detected in E13.5 $\mathrm{Tb} x 5^{\text {lox/lox }}$; Prx1Cre mice (E). Herniation of the internal organs following the failure of body wall closure is present in B and E (asterisk). Figure adapted from [8].

In the developing forelimb, Tbx5 is essential for limb bud initiation [9] and directly activates expression of fibroblast growth factor (FGF), Fgf10 [10], which subsequently activates Fgf8 expression in the apical ectodermal ridge (AER) to establish a FGF signalling positive feedback-loop that maintains limb bud outgrowth [11,12]. Once this FGF feedback loop is established, $T b x 5$ is no longer required for limb bud outgrowth [13]. The Tbx5 targets that control the ventrolateral migration of precursors to form sternal bands remain unknown but it is clear that the activity of $T b x 5$ in regulating migration of sternal precursors is independent of its role in establishing FGF expression since, although Fgf10 $0^{-/-}$mutants fail to develop forelimbs, similar to the Tbx5 conditional knockout mice, the sternum develops normally (Figure 1) [8]. Reduced expression of the gap junction protein, Cx40, is also seen in Tbx5 mutant mice and has been attributed to the sternum defects found in Holt-Oram syndrome [14]. Cx40 is expressed in the migrating sternal bands and colocalises with Tbx5 in the sternal perichondrium. The regulation of $C x 40$ by $T b x 5$ is required for normal sternum development [14].

Following the completion of the migration of the sternal precursor cells, the sternal bands make contact ventrally followed by a progressive cranial to caudal fusion [15,16]. The cells differentiate into chondrocytes, which synthesise cartilage to successfully fuse the sternal bands. A failure in the fusion of the paired mesodermal bands in the ventral midline can result in congenital sternal cleft [17]. This failure of sternal fusion can leave internal organs vulnerable, such as in the rare congenital abnormality ectopia cordis, where the heart bulges out from the chest [18]. More commonly, defects in sternal fusion lead to abnormalities where the sternum (and chest) protrude, pectus carinatum, or is sunken inward, pectus excavatum. A sternal foramen, which is a small hole remaining in the sternum, is also believed to be caused by defects in sternal band fusion. The sternum is an endochondral bone and once the sternal bars have fused a cartilaginous sternum template forms, which subsequently ossifies. This later ossification event is initially controlled through the transcription factor Runx1, which activates Sox 5 and Sox 6 to commit mesenchymal cells to become chondrogenic $[19,20]$. Skeletogenesis in the majority of bones of the body is 
regulated by Runx2, with Runx1 only having a role in the development of the sternum and some parts of the skull [19].

The investigation of mouse mutants with sternal defect phenotypes has identified genes that have a role in sternum development. In knockout Early B-cell factor 3 (Ebf3) mice, the ossification of the sternum fails but chondrogenesis remains unaffected. Ebf 3 is required to generate Runx2+ pre-osteoblasts from their progenitors in the LPM for the commitment of sternal ossification [21]. In $\operatorname{Pax}^{--} \mathrm{Pax9}^{-/}$double knockout mutant mouse embryos analysed at E12.5, the morphology of the sternum is disrupted. The Paired-box genes Pax1 and Pax9 regulate cell proliferation, collagen fibrillogenesis, cartilage development and are thought to be important for mesenchymal condensation [22]. Different mutations in the Hoxb4 gene result in different phenotypes in mouse mutants. A severe Hoxb $4^{r}$ allele mutation leads to sternal abnormalities where the sternal bands fail to fuse correctly in homozygous mice, leading to the proposal that Hoxb4 directs the ventromedial migration of the sternal bands [15]. While these genes have been associated with sternal defects in knockout studies and genetic diseases, their precise function in sternal development remains unclear.

\subsection{Sternal Adaptations in Vertebrates}

The earliest fossil evidence of the sternum dates back over 400 million years ago to the Devonian period. Primitive cartilaginous sternabrae have been described in an early tetrapod, Ichthyostega [23]. Ichthyostega is thought to have had a limited range of movement, therefore this structural adaptation could have helped to reinforce the ribcage, allowing the animal to balance its bodyweight onto its chest [23]. The sternabrae have no evidence of articulation with the ribs and the animal could not lift itself off the ground, a defining feature of tetrapods with a sternum. In extant reptiles, such as lizards and crocodiles, the sternum remains cartilaginous and is a flat elongated structure forming joints with the clavicles and to multiple pairs of ribs, depending on the species. A minority of vertebrates have adapted to terrestrial life without a sternum, such as the turtle [24], which instead has acquired extended ribs integrated into its specialised carapace [25]. In snakes, caecilians and legless lizards that have undertaken complete forelimb reduction, the sternum is absent [26]. However, the squamate reptiles amphisbaenians, excluding the species Bipes biporus, have undertaken complete forelimb reduction and are found with a vestigial cartilaginous sternum [27]. The first evidence of an ossified sternum is described in fossils of the Anomodontia, an extinct group of non-mammalian therapsids dating from the Permian and Triassic periods, approximately 200 million years after the Devonian [28]. An ossified sternum is also found in the non-avian maniraptoran dinosaur groups oviraptorosauria and dromaeosauridae, despite its absence in the Mesozoic birds Archaeopteryx and Sapeornis, suggesting the common ancestor between these two groups most probably did not have an ossified sternum [29].

Tetrapods that predominantly use their hindlimbs, such as the kangaroo, have noticeably reduced forelimbs and a shortened sternum, relative to their body size. Comparatively, tetrapods with dominant forelimbs, such as the fossorial marsupial 'mole' (Notoryctes) and convergently evolved common mole (Scalopus Aquaticus), have enlarged sterna where the width of its manubrium is almost double its length [30] in addition to an extended keel, which articulates with the clavicles [31]. These adaptations to assist fossorial living strengthen and shorten both the marsupial and common mole forelimbs without compromising leverage, so the forelimbs can act as shovels and levers for pushing dirt away rapidly over long periods.

\subsection{Sternal Morphology Associated with Powered Flight}

Some of the most striking adaptations to sterna occur in vertebrates that undertake powered flight. This locomotory ability has evolved in three evolutionary distinct vertebrate lineages including aves, bats (Chiropterans) and the extinct Pterosauria. Despite being phylogenetically diverse, they have all undertaken similar morphological adaptations to 
expand the surface area needed for the attachment of flight muscles. These adaptations include expansion of forelimb skeletal elements to produce a large wing, and an elongated sternum and ventral keel that increases the surface area for the attachment of the enlarged flight muscles, $m$. pectoralis and $m$. supracoracoideus. Analysis of the pectoral girdle of early birds, such as in the Archaeopteryx, the m. supracoracoideus is thought to originate on the coracoid. Over the course of evolution the origin of the m. supracoracoideus moved onto the sternum and is hypothesized to contribute to the evolution of a sternal keel [32]. In birds and bats, which have both evolved powered flight convergently, there is an analogous delay in the ossification event during the development of the sternum when compared to non-volant mammals, suggesting the same regulatory events are conserved and have been adapted for flight in both taxa [33]. Despite being the first vertebrates to undertake powered flight, there are very few records of preserved pterosaur sternum due to their very fragile nature. The very few intact pterosaur sterna are found with a thin sternal plate occupying varying sizes and morphology, commonly with a rectangular or rounded triangular shaped sternal plate with a sternal crest projecting on the ventral sternum [34]. There are three different wing attachments found across pterosaurs that are present with adapted glenoid and facet articulations. High-winged pterosaurs have a dorsolaterally orientated sternocoracoidal facet, whilst lower winged pterosaurs have shallow facets that are laterally orientated [35].

Over the last 150 million years, aves have displayed significant adaptation and diversification, with over 10,000 extant species across the world [36]. The relationship between forelimb use and sternum size has been analysed in a diverse selection of birds that use different forms of locomotion to quantify whether sternal dimensions correlate with flight ability [8]. The developmental events of sternum formation in extant birds appear to have been conserved from early ornithuromorphs, with sterna developing from a bilateral pair of condensations or sternal bands. Basal birds amongst the ornithuromorph group have a comparable sternal morphology to the closely related enantiornithes, but from observing examples from the fossil record, the pattern of sternum ossification identified in these groups are different. The enanthiornithe sternum develops from many ossification events (four to six), with the direction of ossification continuing in the opposite direction (distalproximal) to modern birds [29]. Flightless ratites derive their name from the Latin ratis, meaning raft, a vessel with no keel. These birds exhibit a completely flattened sternum (Figure 2A-C) and their wing size and pectoral muscle mass is also reduced. Similarly, the galapagos cormorant has a flat sternum, a flightless species of cormorant that, when diving, propels itself through the water using its feet (Figure 2D). Despite the kakapo and the extinct, dodo, having also lost their flying ability, a sternal keel is still present, although it is greatly reduced (Figure 2E,F).

In birds, the $m$. pectoralis is much larger than the $m$. supracoracoideus, as the former is involved in generating the power downstroke that generates lift, while the latter is involved largely in providing the upstroke. For example, in the European starling (Sturnus vulgaris) the volume of the $m$. pectoralis is seven times greater than that of $m$. supracoracoideus [37]. Hummingbirds (Trochilidae) are a family of birds that have exceptional flying abilities. They can produce very high frequency wing strokes, fly backwards and maintain hovering flight due to advanced wing joint adaptations to allow axial rotation [38] and by producing lift during both the downstroke and upstroke action of the wings [39,40]. The m. supracoracoideus, which provides the power upstroke in hummingbirds, is greatly enlarged and is approximately half the size of the $m$. pectoralis [41]. To provide the necessary attachment site for these two flight muscles, the sternal keel in the hummingbird is greatly extended (Figure 2G-I) compared to thorax length. Similarly to the hummingbird, the parrot has adapted large wing elevator muscles to support upward aerodynamic forces during upstroke to support vertical locomotion in forest habitats [42]. Strikingly, a sternal keel is present in some aerially flightless birds, such as penguins and the flightless auk (Figure 2J-M). Although these species are not capable of powered flight, they 'fly' through the water using their wings as the means of propulsion, which can explain the requirement 
for a large pectoral muscle mass and associated sternal attachment surface area to resist underwater drag. Contrastingly, aquatic mammals, including the extinct aegicetus [43] and the extant bowhead whale [44] have a broad, flat sternum without a keeled structure. During swimming, whales are hindlimb dominant to propel themselves through the water, with their forelimb structures only assisting any changes in direction. These examples illustrate the correlation between forelimb-driven locomotion and sternal morphology.

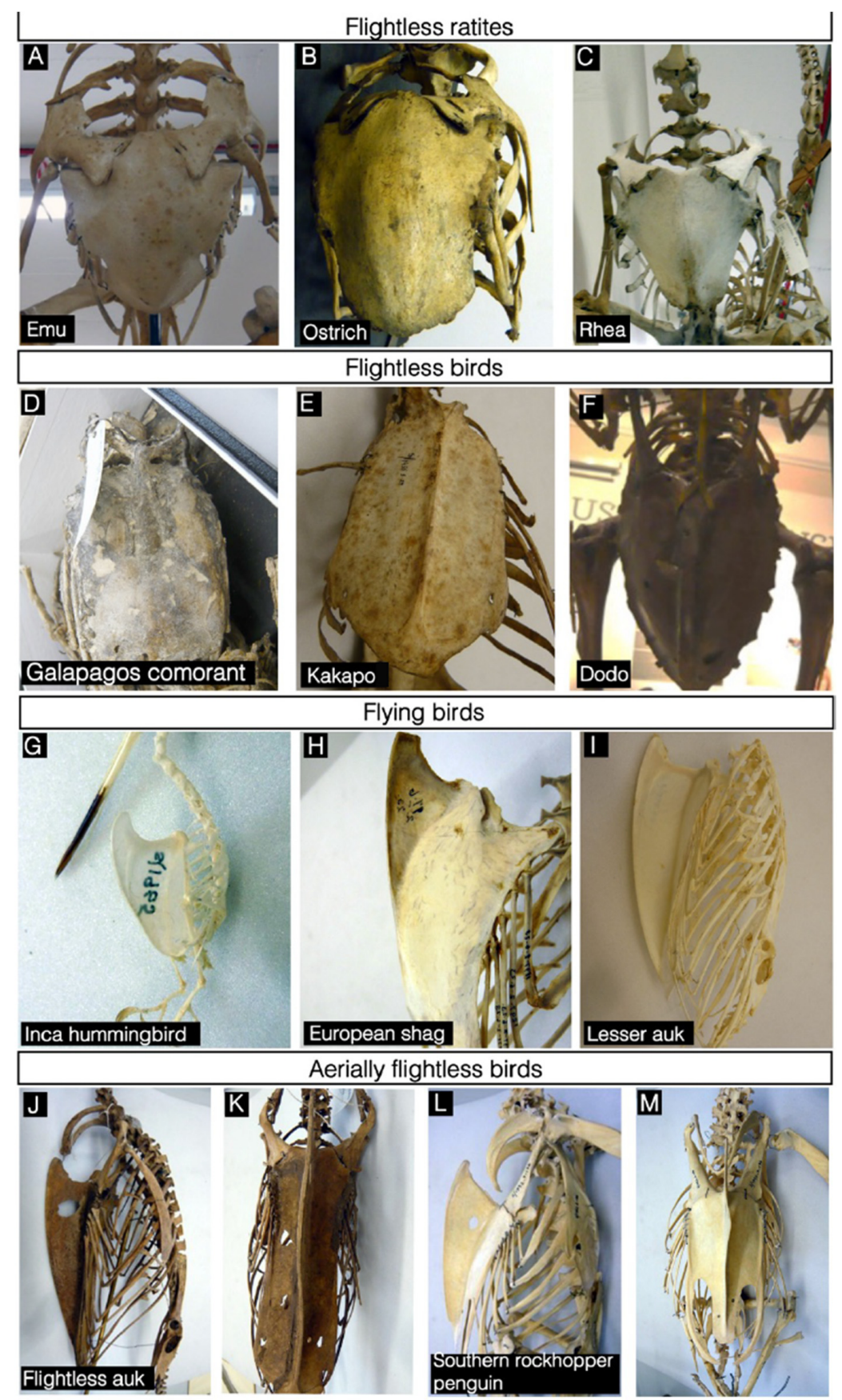

Figure 2. Sternal morphology in flightless and flying birds. Photographs of skeleton preparations of sterna in a diverse range of birds, orientated anteriorly $((\mathbf{A}-\mathbf{F}),(\mathbf{K})$ and $(\mathbf{M}))$ or laterally $((\mathbf{G}-\mathbf{I}),(\mathbf{J})$ and (L)). In flightless ratites and birds such as the emu, ostrich, rhea and galapagos comorant the sternum is flat with the absence of a ventral sternal keel extension (A-D). The flightless kakapo and Dodo have a reduced sternal keel (E,F). In flying birds, including the Inca hummingbird, European Shag and Lesser auk the sternal keel is greatly extended ventrally $(\mathbf{G}-\mathbf{I})$. The aerially flightless southern rockhopper penguin $(\mathbf{J}, \mathbf{K})$ and flightless auk $(\mathbf{L}, \mathbf{M})$ have an extended sternal keel, when viewed ventrally the keel is curved $(\mathbf{K}, \mathbf{M})$. 
The sternal keel of the Magellanic penguin can remodel during the lifetime of the animal. Juvenile penguins have a straight keel while curvatures found in mature penguin skeletons are suggested to result from uneven forces exerted from swimming, if the penguin has a dominant flipper [45]. We have observed similar curved features on the sternal keels of adult specimens of the southern rockhopper penguins and the flightless auk (Figure 2J-M), supporting a model that biomechanical forces generated during locomotion can modify adult sternal keel morphology in different species.

To quantitatively examine the relationship between forelimb use and sternum dimensions, the length and width of the sternum, and the maximum height of the sternal keel have been measured and compared in specimens of groups of birds with a variety of flying abilities [8]. To normalise for the range of body sizes in the groups measured, sternum dimensions were divided by measurements of thorax length, as a representation of overall body size. Normalised skeleton measurements for each selected bird plotted onto scatter graphs show a strong positive correlation between keel height and sternum length (Figure 3A taken from [8]), with stronger fliers, such as pigeons and hummingbirds having larger sterna, while poorer fliers and flightless birds have smaller sterna. A similar correlation is observed between sternum width and keel height (Figure 3B), although this is weaker than that seen for sternum length. This may reflect sternum length being more important in determining available surface area for pectoral muscle attachment. The sternum length and keel height determine the total surface area of the keel, while sternum width does not directly influence keel area. Sternum length may, therefore, show a stronger correlation with keel height, while sternum width may be less affected by the constraint of muscle attachment area and may vary more according to other factors such as balance, body shape, or weight. Together, the data demonstrate that sternum length, and to a lesser extent, sternum width, increase in proportion with keel height in groups of varying flight ability. None of the species measured showed very long sterna with a short keel or vice versa, which suggests that these features are evolutionarily constrained by the attachment of flight muscles.

Flightless birds generally have flattened, shorter sterna than flighted birds, occupying the lower left region of the graphs (Figure 3). However, three of the flightless birds show relatively larger sterna than other flightless birds (solitaire, kakapo and dodo). This may reflect the reported use of the wings or sternum in display, fighting or balance, which has led to these species retaining a larger sternum and more pectoral muscle mass [46,47]. The correlation between sternum dimensions in flightless birds is generally weaker than for flying birds, with the points on the graphs fitting less closely to the line of best fit (Figure 3). This may reflect the reduced evolutionary constraint placed on sternum dimensions in birds that no longer require large flight muscles.

Diving birds, auks, and cormorants, lie on the same trend line as land birds (Figure 3). Auks generally have relatively longer sterna with a taller keel than cormorants (while sternum width is similar), which may be due to the use of their wings for locomotion in both air and underwater, while cormorants use their wings solely in flight and their feet for underwater propulsion. The flightless cormorant, which does not use its wings for locomotion in either air or water lies closer to the other flightless birds, but in contrast, penguins, which are also aerially flightless, have a similar sternum size to flighted species. A reason for this difference is that penguins still require powerful pectoral muscles for flying underwater and therefore have a larger sternum, while the flightless cormorant does not use its wings for flight or diving, and this is reflected by a reduced sternum size. 


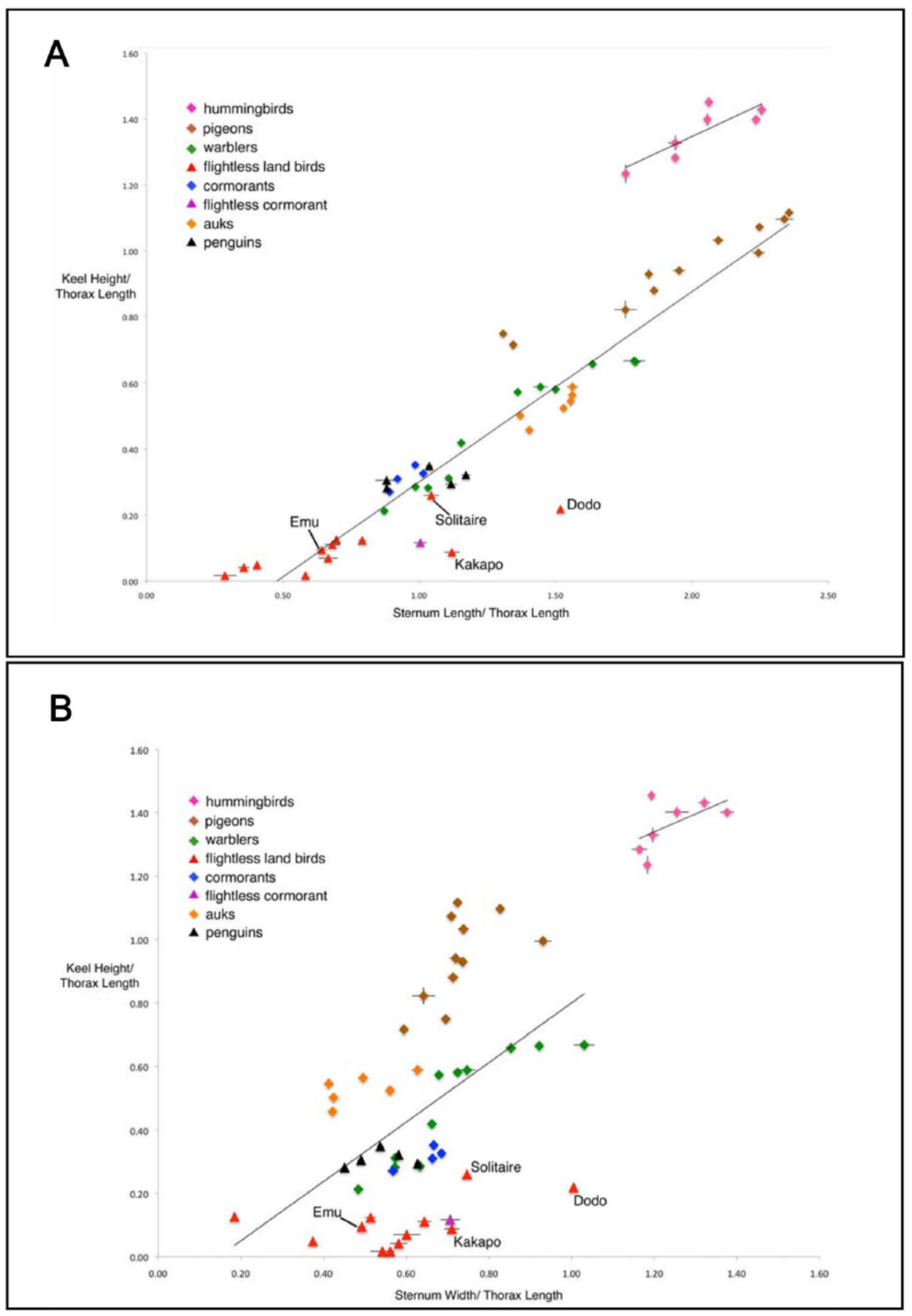

Figure 3. (A): Sternum length and keel height are correlated with mode of locomotion in birds. Scatterplot of measurements for sternum length and keel height, normalised for bird size by dividing by thorax length, for a range of bird groups. Each point on the graph represents one species. When possible multiple specimens were measured per species. Error bars show standard error between multiple specimen measurements. Flying species are represented as diamonds, flightless species as triangles. (B): Sternum width and keel height are correlated with mode of locomotion in birds. Scatterplot showing measurements for sternum width and keel height, normalised for bird size by diving by thorax length, for a range of bird groups. Each point on the graph represents one species. Where possible multiple specimens were measured per species. Error bars show standard error between multiple specimen measurements. Flying species are represented as diamonds, aerially flightless species as triangles. Figure adapted from [8]. 
Most of the species studied cluster along a single line of best fit for sternum length and keel height (Figure 3, lower trend line). However, hummingbirds cluster on a different trend line, having a taller keel but similar, proportional sternum length to pigeons (Figure 3, upper trend line). This may reflect an extreme adaptation to facilitate their high frequency wing strokes and ability to hover. Hummingbird flight muscles represent a significantly larger proportion of the total body muscle mass than in other birds and the supracoracoideus muscle is particularly well developed to generate sufficient force to power the upstroke required for hovering [48]. This increased muscle mass requires a larger attachment surface area, generated by a greater sternal keel height. The sternal length is not proportionally greater in hummingbirds than pigeons, which may indicate an upper limit to sternum length. Therefore, to gain a greater muscle attachment surface area, hummingbirds show an increased keel height relative to their sternum length. Hummingbird sternum width does not show the same constraint as sternum length, and hummingbirds have significantly wider sterna than pigeons (Figure 3B).

These data provide a quantitative demonstration that sternum dimensions are linked with mode of locomotion, and more specifically, with forelimb use. This also suggests that the wing musculature required for flying and in some birds that hunt for prey, by diving, are similar, since the sternum proportions of the flightless wing-propelled divers studied are similar to those of flying birds.

\subsection{Common Genetic Mechanisms Underlying Sternum and Forelimb Development and Adaptation in Ratites}

Most vertebrates show some degree of heterochrony between the appearance of the forelimb and hindlimb buds. The forelimb buds are usually morphologically distinguishable before the hindlimb, mirroring the general trend during early embryogenesis that cranial structures are formed before more caudal ones. Therefore, at these early stages, structures forming in cranial locations are developmentally more mature than those positioned more caudally. In marked contrast however, formation of the emu forelimb bud is delayed compared to the hindlimb [8,49-51]. At the other extreme, marsupials form precocial forelimbs which help them to climb to the teat after birth. During embryogenesis the marsupial forelimb development programme is initiated early, including an acceleration in the activation of Tbx5 expression in the LPM [52].

In addition to a reduction in the sternum, the emu has a reduced mature wing with a single digit, compared with the majority of birds having 3 wing digits, whilst the developing emu has a four-digit pattern when analysing chondrogenic markers [53]. A delay in the onset of Tbx5 expression in the emu forelimb-forming region has been proposed to explain the delay in the appearance of the emu forelimb bud and to contribute to a reduction in sternum and wing size in the emu [8]. Since Tbx5 has essential roles in both sternum and forelimb development, it provides a common node for potential regulatory modulation that would impact both these elements. It is known that Tbx5 acts within the cells of the forelimbforming LPM during a narrow time-window of competence to establish the FGF-signalling feedback loop that is critical to establish and maintain limb bud outgrowth [54,55]. A delay in establishing Tbx5 expression could lead to the recruitment of a smaller cohort of limb bud precursors, resulting in a smaller limb. A reduced cohort of progenitors could similarly explain the reduction in sternum size. In addition, a failure of these progenitors to migrate to the ventral midline could also lead to a smaller sternum. This model has been challenged by studies that report no delay in the initiation of emu Tbx5 expression in the forelimb. However, both studies [51,56] only report Tbx5 expression in emu at Hamburger-Hamilton $(\mathrm{HH})$ equivalent stages 18/19 and older, while the original study describes a clear delay in the onset of Tbx5, which can be detected in chick from at least HH16 and at the equivalent stages in the emu there is no expression of $T b x 5$ [8].

A different study has proposed an alternative model, where an alteration to the normal expression of the downstream target of Tbx5, Fgf10, is responsible for the forelimb developing later and the reduced wing size [51]. Changes to the regulatory sequences at the emu Fgf10 locus leads to a reduction in expression levels that causes lower levels of 
proliferation in limb mesenchymal cells. Since a normal sternum can form in the mouse Fof10 null mutant and Fof10 expression is not detected in the region of cells fated to form the sternum, it appears that any regulatory mutations at the Fgf10 locus while expected to impact the wing elements, would not impact sternum development.

An apparent regulatory adaptation of $N k x 2.5$ expression in the developing emu forelimb has been proposed to contribute to an inhibition of limb bud and later limb muscle growth, by reducing cell proliferation [40]. However, this mechanism is not responsible for the initial delay in emu wing bud formation. The co-option of $N k x 2.5$ expression in the emu forelimb is not observed in other ratites, such as the ostrich, indicating that there are at least two mechanisms employed for wing reduction within ratites. This may suggest that flightless species may employ multiple mechanisms that act in combination to downregulate the forelimb programme and while some may be shared, others can be unique to a particular species.

The exact mechanisms causing reduction in the wing and sternum in emu remains in debate. While the three main studies discussed above propose different explanations for the reduction in the forelimb programme in the emu, all agree that there is a delayed onset of limb budding $[8,51,56]$. There are many examples of reduction in the forelimb programme in extinct and extant tetrapods. Flightless bird species have arisen in different bird families, and phylogenetic evidence suggests that flight has been lost multiple times independently even within ratites [57]. Whether the similar adaptations to sternum and wing elements observed in all these species have been established through targeting the same or a several gene loci remains to be established. The acquisition of mutations in limb regulatory elements that cause limb reduction would result in a loss of selective pressures to retain limb regulatory elements at other gene loci. Therefore, one can expect that over time, additional secondary regulatory mutations would have been acquired that did not contribute to the reduction in the limb programme. A key experimental challenge therefore will be to distinguish the regulatory changes that were primarily responsible for the reduction in the forelimb programme from those that could have occurred at many loci after limb loss, with the available genomic data from extant animals.

Author Contributions: S.R.B.B. collected and analysed original data. E.M.F. and M.P.O.L. analysed data and wrote the review. All authors have read and agreed to the published version of the manuscript.

Funding: M.P.O.L.: S.R.B.B. funded by Medical Research Council (MRC) MC_PC_13052. M.P.O.L. and E.M.F. funded by Medical Research Council (MRC) MR/S000038/1.

Institutional Review Board Statement: Not applicable.

Informed Consent Statement: Not applicable.

Data Availability Statement: All datasets are available from Professor Malcolm Logan.

Acknowledgments: We thank Jo Cooper (Natural History Museum of Tring) and Robert Asher and Matt Lowe (Cambridge University Museum of Zoology) for making their collection of avian skeletons available.

Conflicts of Interest: The authors declare no conflict of interest.

\section{References}

1. Amaral, D.B.; Schneider, I. Fins into limbs: Recent insights from sarcopterygian fish. Genesis 2018, 56, e23052. [CrossRef]

2. Wang, K.; Wang, J.; Zhu, C.; Yang, L.; Ren, Y.; Ruan, J.; Fan, G.; Hu, J.; Xu, W.; Bi, X.; et al. African lungfish genome sheds light on the vertebrate water-to-land transition. Cell 2021, 184, 1362-1376. [CrossRef]

3. Bi, X.; Wang, K.; Yang, L.; Pan, H.; Jiang, H.; Wei, Q.; Fang, M.; Yu, H.; Zhu, C.; Cai, Y.; et al. Tracing the genetic footprints of vertebrate landing in non-teleost ray-finned fishes. Cell 2021, 184, 1377-1391. [CrossRef]

4. Luo, Z. Origins of the Mammalian Shoulder; The University of Chicago Press: Chicago, IL, USA, 2015; pp. $167-187$.

5. Clack, J.A. Gaining Ground: The Origin and Evolution of Tetrapods; Indiana University Press: Bloomington, IN, USA, 2002; pp. $487-488$.

6. Seno, T. The origin and evolution of the sternum. Anat. Anzeiger. 1961, 110, 97-101. 
7. Li, Q.Y.; Newbury-Ecob, R.A.; Terrett, J.A.; Wilson, D.; Curtis, A.R.; Yi, C.H.; Gebuhr, T.; Bullen, P.J.; Robson, S.C.; Strachan, T.; et al. Holt-Oram syndrome is caused by mutations in TBX5, a member of the Brachyury (T) gene family. Nat. Genet. 1997, 15, 21-29. [CrossRef] [PubMed]

8. Bickley, S.R.; Logan, M.P. Regulatory modulation of the T-box gene Tbx5 links development, evolution, and adaptation of the sternum. Proc. Natl. Acad. Sci. USA 2014, 111, 17917-17922. [CrossRef] [PubMed]

9. Agarwal, P.; Wylie, J.N.; Galceran, J.; Arkhitko, O.; Li, C.; Deng, C.; Grosschedl, R.; Bruneau, B. Tbx5 is essential for forelimb bud initiation following patterning of the limb field in the mouse embryo. Development 2003, 130, 623-633. [CrossRef] [PubMed]

10. Ng, J.K.; Kawakami, Y.; Büscher, D.; Raya, A.; Itoh, T.; Koth, C.M.; Esteban, C.R.; Leon, J.M.R.; Garrity, D.M.; Fishman, M.C.; et al. The limb identity gene Tbx5 promotes limb initiation by interacting with Wnt2b and Fgf10. Development 2002, 129, 5161-5170. [CrossRef]

11. Hasson, P.; DeLaurier, A.; Bennett, M.; Grigorieva, E.; Naiche, L.A.; Papaioannou, V.; Mohun, T.J.; Logan, M.P. Tbx4 and Tbx5 Acting in Connective Tissue Are Required for Limb Muscle and Tendon Patterning. Dev. Cell 2010, 18, 148-156. [CrossRef]

12. Xu, X.; Weinstein, M.; Li, C.; Naski, M.; I Cohen, R.; Ornitz, D.M.; Leder, P.; Deng, C. Fibroblast growth factor receptor 2 (FGFR2)-mediated reciprocal regulation loop between FGF8 and FGF10 is essential for limb induction. Development 1998, 125, 753-765. [CrossRef]

13. Hasson, P.; Del Buono, J.; Logan, M.P.O. Tbx5 is dispensable for forelimb outgrowth. Development 2007, 134, 85-92. [CrossRef] [PubMed]

14. Pizard, A.; Burgon, P.G.; Paul, D.L.; Bruneau, B.G.; Seidman, C.E.; Seidman, J.G. Connexin 40, a Target of Transcription Factor Tbx5, Patterns Wrist, Digits, and Sternum. Mol. Cell. Biol. 2005, 25, 5073-5083. [CrossRef]

15. Ramfrez-Solis, R.; Zheng, H.; Whiting, J.; Krumlauf, R.; Bradley, A. Hoxb-4 (Hox-2.6) mutant mice show homeotic transformation of a cervical vertebra and defects in the closure of the sternal rudiments. Cell 1993, 73, 279-294. [CrossRef]

16. Chen, J.M. Studies on the morphogenesis of the mouse sternum. I. Normal embryonic development. J. Anat. 1952, 86, 373-386. [PubMed]

17. Eijgelaar, A.; Bijtel, J.H. Congenital cleft sternum. Thorax 1970, 25, 490-498. [CrossRef]

18. Gabriel, A.; Donnelly, J.; Kuc, A.; Good, D.; Doros, G.; Matusz, P.; Loukas, M. Ectopia cordis: A rare congenital anomaly. Clin. Anat. 2014, 27, 1193-1199. [CrossRef]

19. Liakhovitskaia, A.; Lana-Elola, E.; Stamateris, E.; Rice, D.P.; van Hof, R.J.; Medvinsky, A. The essential requirement for Runx1 in the development of the sternum. Dev. Biol. 2010, 340, 539-546. [CrossRef]

20. Kimura, A.; Inose, H.; Yano, F.; Fujita, K.; Ikeda, T.; Sato, S.; Iwasaki, M.; Jinno, T.; Ae, K.; Fukumoto, S.; et al. Runx1 and Runx2 cooperate during sternal morphogenesis. Development 2010, 137, 1159-1167. [CrossRef]

21. Kuriki, M.; Sato, F.; Arai, H.N.; Sogabe, M.; Kaneko, M.; Kiyonari, H.; Kawakami, K.; Yoshimoto, Y.; Shukunami, C.; SeharaFujisawa, A. Transient and lineage-restricted requirement of Ebf3 for sternum ossification. Development 2020, 147. [CrossRef]

22. Sivakamasundari, V.; Kraus, P.; Sun, W.; Hu, X.; Lim, S.L.; Prabhakar, S.; Lufkin, T. A developmental transcriptomic analysis of Pax1 and Pax9 in embryonic intervertebral disc development. Biol. Open 2016, 6, 187-199. [CrossRef]

23. Pierce, S.E.; Ahlberg, P.E.; Hutchinson, J.R.; Molnar, J.L.; Sanchez, S.; Tafforeau, P.; Clack, J.A. Vertebral architecture in the earliest stem tetrapods. Nature 2013, 494, 226-229. [CrossRef] [PubMed]

24. Rice, R.; Kallonen, A.; Cebra-Thomas, J.; Gilbert, S.F. Development of the turtle plastron, the order defining skeletal structure Proc. Natl. Acad. Sci. USA 2016, 113, 5317-5322. [CrossRef] [PubMed]

25. Gilbert, S.F.; Loredo, G.A.; Brukman, A.; Burke, A.C. Morphogenesis of the turtle shell: The development of a novel structure in tetrapod evolution. Evol. Dev. 2001, 3, 47-58. [CrossRef]

26. Gladstone, R.J.; Wakeley, C.P.G. The Morphology of the Sternum and its Relation to the Ribs. J. Anat. 1932, 66, 508-564. [PubMed]

27. Westphal, N.; Mahlow, K.; Head, J.J.; Muller, J. Pectoral myology of limb reduced worm lizards (Squamata, Amphisbaenia) suggests decoupling of the musculoskeletal system during the evolution of body elongation. BMC Evol. Biol. 2019, 19, 16. [CrossRef]

28. Broom, R. On a nearly complete therocephalian skeleton. Ann. Transvaal Mus. 1938, 9, 1-5.

29. Zheng, X.; Wang, X.; O'Connor, J.; Zhou, Z. Insight into the early evolution of the avian sternum from juvenile enantiornithines. Nat. Commun. 2012, 3, 1116. [CrossRef]

30. Warburton, N.M. Functional Morphology of Marsupial Moles (Marsupialia; Notoryctidae); Verhandlungen des Naturwissenschaftlichen Vereins: Hamburg, Germany, 2006; pp. 39-149.

31. Edwards, L.F. Morphology of the Forelimb of the Mole (Scalops aquaticus, L.) in Relation to Its Fossorial Habits. Ohio J. Sci. 1937, 37, 20-41.

32. Mayr, G. Pctoral girdle morphology of Mesozoic birds and the evolution of the avian supracoricodius muscle. J. Ornithol. 2017, 158, 859-867. [CrossRef]

33. López-Aguirre, C.; Hand, S.J.; Koyabu, D.; Son, N.T.; Wilson, L.A.B. Postcranial heterochrony, modularity, integration and disparity in the prenatal ossification in bats (Chiroptera). BMC Evol. Biol. 2019, 19, 75. [CrossRef]

34. Geist, N.R.; Hillenius, W.I.; Frey, E.; Jones, T.D.; Elgin, R.A. Breathing in a box: Constraints on lung ventilation in giant prerosaurs. Anat. Rec. 2014, 297, 2233-2253. [CrossRef] [PubMed]

35. Frey, E.M.B.; Mertill, D.M. Middle and Bottom Decker Cretaceous pterosaurs: Unique Designs in Active Flying Vertebrates; Geological Society: Bath, UK, 2003; pp. 267-274. 
36. Brusatte, S.L.; O'Connor, J.K.; Jarvis, E.D. The Origin and Diversification of Birds. Curr. Biol. 2015, 25, R888-R898. [CrossRef]

37. Sullivan, S.P.; McGechie, F.R.; Middleton, K.M.; Holliday, C.M. 3D Muscle Architecture of the Pectoral Muscles of European Starling. Integr. Org. Biol. 2019, 1, oby010. [CrossRef] [PubMed]

38. Zusi, R.L. Introduction to the Skeleton of Hummingbirds (Aves: Apodiformes, Trochilidae) in Functional and Phylogenetic Contexts. Ornithol. Monogr. 2013, 77, 1-94. [CrossRef]

39. Wolf, M.; Ortega-Jimenez, V.M.; Dudley, R. Structure of the vortex wake in hovering Anna's hummingbirds (Calypte anna). Proc. Biol. Sci. 2013, 280, 20132391. [CrossRef]

40. Warrick, D.R.; Tobalske, B.W.; Powers, D. Aerodynamics of the hovering hummingbird. Nature 2005, 435, 1094-1097. [CrossRef]

41. Biewener, A.A. Muscle function in avian flight: Achieving power and control. Philos. Trans. R. Soc. B Biol. Sci. 2011, 366, 1496-1506. [CrossRef]

42. Razmadze, D.; Panyutina, A.; Zelenkov, N.V. Anatomy of the forelimb musculature and ligaments of Psittacus erithacus (Aves: Psittaciformes). J. Anat. 2018, 233, 496-530. [CrossRef]

43. Gingerich, P.D.; Antar, M.S.M.; Zalmout, I.S. Aegicetus gehennae, a new late Eocene protocetid (Cetacea, Archaeoceti) from Wadi Al Hitan, Egypt, and the transition to tail-powered swimming in whales. PLoS ONE 2019, 14, e0225391. [CrossRef]

44. Struthers, J. The Form of the Sternum in the Greenland Right-Whale (Balcna mysticetus). J. Anat. Physiol. 1895, $29,593-612$. [PubMed]

45. Stor, T.; Rebstock, G.A.; Borboroglu, P.G.; Boersma, P.D. Lateralization (handedness) in Magellanic penguins. PeerJ 2019 , 7, e6936. [CrossRef]

46. Strickland, H.E.; Melville, A.G. The Dodo and Its Kindred; or, the History, Affinities, and Osteology of the Dodo, Solitaire, and Other Extinct Birds of the Islands Mauritius, Rodriguez and Bourbon; Strickland, H.E., Melville, A.G., Eds.; Reeve, Benham and Reeve: London, UK, 1848.

47. Livezey, B.C. Morphological corollaries and ecological implications of flightlessness in the kakapo (Psittaciformes: Strigops habroptilus). J. Morphol. 1992, 213, 105-145. [CrossRef] [PubMed]

48. Warrick, D.; Hedrick, T.; Fernandez, M.J.; Tobalske, B.; Biewener, A. Hummingbird flight. Curr. Biol. 2012, 22 , R472-R477. [CrossRef] [PubMed]

49. Nagai, H.; Mak, S.-S.; Weng, W.; Nakaya, Y.; Ladher, R.; Sheng, G. Embryonic development of the emu, Dromaius novaehollandiae. Dev. Dyn. 2011, 240. [CrossRef]

50. Smith, C.A.; Farlie, P.G.; Davidson, N.M.; Roeszler, K.N.; Hirst, C.; Oshlack, A.; Lambert, D.M. Limb patterning genes and heterochronic development of the emu wing bud. EvoDevo 2016, 7, 26. [CrossRef]

51. Young, J.; Grayson, P.; Edwards, S.V.; Tabin, C.J. Attenuated Fgf Signaling Underlies the Forelimb Heterochrony in the Emu Dromaius novaehollandiae. Curr. Biol. 2019, 29, 3681-3691.e5. [CrossRef] [PubMed]

52. Keyte, A.L.; Smith, K.K. Developmental origins of precocial forelimbs in marsupial neonates. Development 2010, 137, 4283-4294. [CrossRef] [PubMed]

53. De Bakker, M.A.; Fowler, D.A.; den Oude, K.; Dondorp, E.M.; Navas, M.C.; Horbanczuk, J.O.; Sire, J.-Y.; Szczerbińska, D.; Richardson, M.K. Digit loss in archosaur evolution and the interplay between selection and constraints. Nature 2013, 500, 445-448. [CrossRef]

54. Duboc, V.; Logan, M.P.O. Regulation of limb bud initiation and limb-type morphology. Dev. Dyn. 2011, 240, 1017-1027. [CrossRef]

55. Sheeba, C.; Logan, M. The Roles of T-Box Genes in Vertebrate Limb Development. Curr. Top. Dev. Biol. 2017, 122, 355-381. [CrossRef]

56. Farlie, P.G.; Davidson, N.M.; Baker, N.L.; Raabus, M.; Roeszler, K.N.; Hirst, C.; Major, A.; Mariette, M.M.; Lambert, D.M.; Oshlack, A.; et al. Co-option of the cardiac transcription factor Nkx2.5 during development of the emu wing. Nat. Commun. 2017, 8, 132. [CrossRef] [PubMed]

57. Harshman, J.; Braun, E.L.; Braun, M.J.; Huddleston, C.J.; Bowie, R.; Chojnowski, J.L.; Hackett, S.J.; Han, K.-L.; Kimball, R.; Marks, B.D.; et al. Phylogenomic evidence for multiple losses of flight in ratite birds. Proc. Natl. Acad. Sci. USA 2008, 105, 13462-13467. [CrossRef] 